\title{
Folate in Milk Fermented by Lactic Acid Bacteria from Different Food Sources
}

\author{
Fenny Amilia Mahara', Lilis Nuraida ${ }^{1,2}$, and Hanifah Nuryani Lioe ${ }^{1}$ \\ ${ }^{1}$ Department of Food Science and Technology, Faculty of Agricultural Engineering and Technology and \\ ${ }^{2}$ Southeast Asian Food and Agricultural Science and Technology (SEAFAST) Center, IPB University (Bogor Agricultural University), \\ Bogor 16680, Indonesia
}

\begin{abstract}
Folates are essential micronutrients, and folate deficiency still occurs in many countries. Lactic acid bacteria (LAB) are known to be able to synthesize folates during fermentation, but the folate production is strain-dependent and influenced by the fermentation medium, presence of a folate precursor, and fermentation time. This study aimed to screen extracellular folate-producing LAB from local food sources and evaluate the factors influencing their folate biosynthesis during milk fermentation. The selection of folate-producing LAB was based on their ability to grow in folate-free medium (FACM), with folate concentrations quantified by microbiological assay. Growth of the 18 LAB in FACM varied between isolates, with only 8 isolates growing well and able to synthesize extracellular folate at relatively high concentrations (up to $24.27 \mathrm{ng} / \mathrm{mL}$ ). The isolates with highest extracellular folate levels, Lactobacillus fermentum JK13 from kefir granules, Lactobacillus plantarum 4C261 from salted mustard, and Lactobacillus rhamnosus R23 from breast milk, were applied to milk fermentation. The last two isolates were probiotic candidates. The three isolates consumed folate when it was present in the milk, and its consumption was in line with their growth. The availability of folate precursors affected the amount of folate consumed, but did not lead to increased folate concentrations in the medium after $72 \mathrm{~h}$ fermentation. The results of this study indicate that these isolates cannot be utilized for producing folate in folate-containing milk, as it shows feedback inhibition on folate biosynthesis.
\end{abstract}

Keywords: folate, folate precursor, lactic acid bacteria, milk fermentation, probiotic

\section{INTRODUCTION}

Folate, especially in the forms of tetrahydrofolate (THF) and methyl-tetrahydrofolate (MTHF), is in the water-soluble vitamin $B$ group, and it is the essential cofactor in carbon-1 transfer reactions for the synthesis of DNA, nucleic acids, amino acids, and other vitamins (Crider et al., 2012; Laiño et al., 2015). The body requires a certain amount of folate, particularly during growth and pregnancy (Crider et al., 2011). Folate deficiency during pregnancy has been associated with many adverse effects such as miscarriage, preeclampsia, prematurity, low birth weight, stillbirth, and neural tube defects (Castaño et al., 2017). Inadequate folate levels in the body can also lead to megaloblastic anemia, homocysteinemia, cardiovascular diseases, and some types of cancer (Wright et al., 2007).

Folate can be found in a broad range of foods; however, washing and processing can reduce the amount of folate present due to its high water solubility, instability, and easy oxidative degradation (Delchier et al., 2016; Saini et al., 2016). Additionally, some population groups such as the elderly and children have a higher risk of folate deficiency due to their low dietary intake and less diverse food consumption (Laiño et al., 2013). Therefore, daily food intake cannot meet daily folate requirements.

For decades, fortification and dietary supplementation have been a concern in several countries for preventing folate deficiency, as synthetic folate (folic acid) has more stable properties (Laiño et al., 2014). However, the metabolism of synthetic folate in humans is limited due to a requirement for a two-step reduction and the low activity of dihydrofolate reductase (DHFR); thus, high doses of folic acid cannot be rapidly metabolized (Patel and Sobczyńska-Malefora, 2017). This can lead to accumulation of unmetabolized folic acid in the blood causing undetected symptoms of vitamin B12 deficiency and even 
trigger cancer (Wright et al., 2007). Due to its potential adverse effects, some countries tend not to mandate the use of synthetic folate (Laiño et al., 2014).

Folate is reportedly produced during fermentation by certain lactic acid bacteria (LAB), with THF and MTHF as the predominant folate forms (Gangadharan et al., 2010; Padalino et al., 2012; Meucci et al., 2018). LAB synthesize folate intracellularly and use it for their cellular growth, but some is also secreted into the growth medium, thereby increasing its folate concentration (Greppi et al., 2017). This extracellular folate can raise folate levels in fermented foods and has the potential to be an alternative source of natural folate without side effects on human health (Laiño et al., 2012; Greppi et al., 2017).

The ability of LAB to synthesize folate varies between strains. The growth of non-folate-producing LAB depends on the availability of folate in the medium (Laiño et al., 2014; Greppi et al., 2017), whereas folate-producing LAB regulate folate biosynthesis, synthesizing folate when it is unavailable in the medium. When folate is present in adequate amounts in the medium, most folate-producing $\mathrm{LAB}$ tend to consume the available folate in the medium rather than synthesize it. Several studies (Sybesma et al., 2003; Pompei et al., 2007) have reported that the presence of folate in a medium can lead to feedback inhibition in most $\mathrm{LAB}$, preventing folate overproduction. However, some LAB over-produce folate and exceed their needs, continuing to produce folate despite its presence in the medium (Pompei et al., 2007).

Apart from being strain-dependent, the ability of LAB to synthesize folate is also affected by other factors such as the fermentation media, presence of folate precursors, and fermentation conditions (Laiño et al., 2012; Divya and Nampoothiri, 2015). Therefore, to support the use of LAB to enrich fermented foods' folate content, the selection of LAB capable of producing and secreting folate into a medium should be combined with a study of the factors affecting their folate production.

The most suitable matrix for applying folate-producing LAB to enriching fermented foods is milk, which supplies the complete nutritional needs of $\mathrm{LAB}$ for growth while having a low folate content of only around $20 \sim 50 \mathrm{ng} / \mathrm{mL}$ (Laiño et al., 2013). The presence of folate-binding proteins in milk would also increase the stability and bioavailability of the folate synthesized by the LAB during fermentation (Nygren-Babol and Jägerstad, 2012).

LABs are known to be present in various foods, both fermented and unfermented. Our research aimed to screen LAB isolated from local food sources (tempe, breast milk, salted mustard, kefir granules, cassava tapai, and sticky rice tapai) for their ability to produce extracellular folate in a folate-free medium and then apply the selected folateproducing LAB to milk fermentation. The effects of folate precursors and fermentation time were also evaluated.

\section{MATERIALS AND METHODS}

\section{Microorganisms and growth conditions}

The LAB used in this study (Table 1) were obtained from the culture collection of the SEAFAST Center, IPB University, Bogor, Indonesia. They were originally isolated from local food sources (tempe, breast milk, salted mustard, kefir granules, cassava tape, and sticky rice tape). Some of these strains have potential as probiotics and for their cholesterol-lowering activity and ability to prevent diarrhea. All isolates were maintained and stored in a mixture of de Man, Rogosa, and Sharpe (MRS) broth (MRSB; CM0359, Oxoid Ltd., Basingstoke, UK) and glycerol $(20 \%)$ at $-20^{\circ} \mathrm{C}$. Prior to use, the isolates were revived in MRSB and incubated at $37^{\circ} \mathrm{C}$ for $24 \mathrm{~h}$.

\section{Inoculum preparation}

The LAB isolates were grown in MRSB at $37^{\circ} \mathrm{C}$ for $24 \mathrm{~h}$, then inoculated onto MRS agar (MRSA; CM0361, Oxoid Ltd.) and incubated at $37^{\circ} \mathrm{C}$ for $48 \mathrm{~h}$. Colonies were harvested using sterile cotton buds, suspended in sterile saline solution $(0.85 \% \mathrm{w} / \mathrm{v} \mathrm{NaCl}$; 106404 , Merck KGaA, Darmstadt, Germany), and washed twice by centrifugation at $10,000 \mathrm{~g}$ for $5 \mathrm{~min}$ at $4^{\circ} \mathrm{C}$, and finally resuspended in sterile saline solution $(0.85 \% \mathrm{w} / \mathrm{v} \mathrm{NaCl}$, Merck KGaA). The cell densities obtained were around 9 10 log colony-forming units $(\mathrm{CFU}) / \mathrm{mL}$, which were diluted to $5 \sim 6 \log \mathrm{CFU} / \mathrm{mL}$ before use as the inoculums.

\section{Growth of folate-producing $\mathrm{LAB}$ in folate-free medium}

The LAB were inoculated (2\%) into folate-free medium (folic acid casei medium, FACM; M543, HiMedia Laboratories, Mumbai, India) containing $2 \mathrm{mg} / \mathrm{L}$ of $p$-aminobenzoic acid (PABA) and into rich folate medium (MRSB) as a control; the cultures were incubated at $37^{\circ} \mathrm{C}$ for 16 h. Growth in the medium was evaluated by measuring $\mathrm{OD}_{580}$. Isolates with high $\mathrm{OD}_{580}$ values and the potential for use as probiotics were selected for measuring their folate production.

\section{$\mathrm{LAB}$ growth and extracellular folate production in folate- free medium}

Inoculum (2\%) for the selected isolates was added to FACM, incubated at $37^{\circ} \mathrm{C}$ for $24 \mathrm{~h}$, and then subcultured twice into fresh media to ensure good growth in FACM. The last subculture was incubated for $16 \mathrm{~h}$ before measuring the folate content in the medium. Researchers (Gangadharan et al., 2010; Meucci et al., 2018) in previous studies that selected folate-producing bacteria have directly measured the folate content in FACM without subculturing. Therefore, we considered subculturing twice to be adequate for the selection of folate-producing LAB. The strains were analyzed for their $\mathrm{LAB}$ counts and folate contents. Isolates with the highest extracellular fo- 


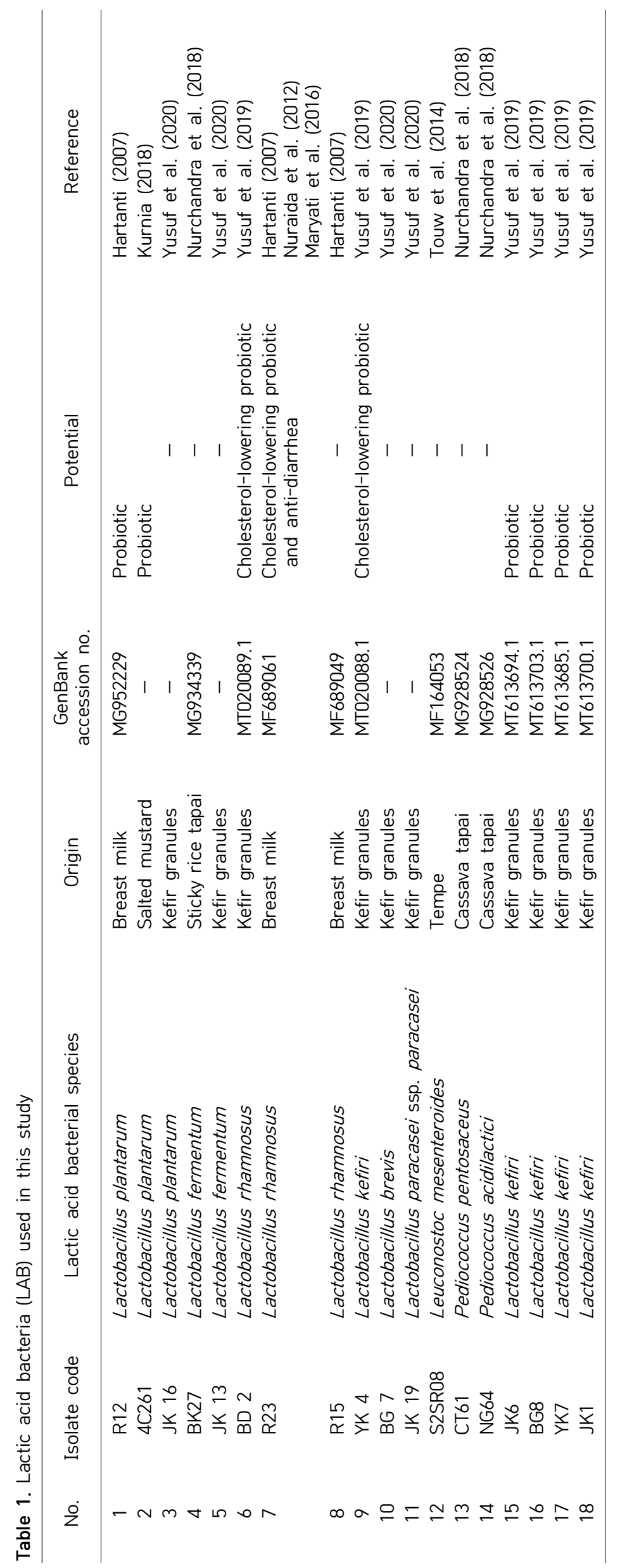


late contents and a known potential for use as probiotics were selected for further stages.

\section{Folate production and LAB growth in reconstituted skim milk}

The selected extracellular folate-producing LAB were applied to fermenting reconstituted skim milk $(12 \% \mathrm{w} / \mathrm{v}$; NZMP Ltd., Auckland, New Zealand) with $2 \%$ inoculations and incubation at $37^{\circ} \mathrm{C}$ for $48 \mathrm{~h}$. Analyses were performed for their folate concentrations, LAB counts, $\mathrm{pH}$, and titratable acidity.

\section{Effect of folate precursors on folate concentration in the fermentation of reconstituted skim milk}

Similarly, the selected LABs were used to ferment reconstituted skim milk supplemented with PABA $(100 \mu \mathrm{mol} /$ L; A9878, Sigma-Aldrich Co., St. Louis, MO, USA) or glutamate $(100 \mu \mathrm{mol} / \mathrm{L}$; G1251, Sigma-Aldrich Co.) as folate precursors, with incubation at $37^{\circ} \mathrm{C}$ for $48 \mathrm{~h}$. The folate content and $\mathrm{pH}$ values were analyzed.

\section{Effect of fermentation time on folate concentration of reconstituted skim milks}

The selected LABs were inoculated into reconstituted skim milk and incubated at $37^{\circ} \mathrm{C}$. Samples were taken at $0,24,48$, and $72 \mathrm{~h}$ for analyses of the folate concentration, $\mathrm{LAB}$ count, $\mathrm{pH}$ value, and titratable acidity.

\section{Folate analysis}

The extraction of extracellular folate from the media was executed according to Lin and Young (2000) with some modifications. For folate-free medium, the extraction process was performed by centrifugation at $10,000 \mathrm{~g}$ for $5 \mathrm{~min}$, while the extraction from fermented milk was done by adding $1 \mathrm{~mL}$ of extraction buffer $(0.1 \mathrm{M}$ phosphate buffer, $0.5 \% \mathrm{w} / \mathrm{v}$ ascorbic acid, $\mathrm{pH} 6.8 ; 100468$, Merck KGaA) to $1 \mathrm{~mL}$ of fermented milk, boiling for 15 $\mathrm{min}$, and centrifuging at $10,000 \mathrm{~g}$ for $5 \mathrm{~min}$. The supernatant was then filtered through a $0.2 \mu \mathrm{m}$ sterile polyethersulfone filter membrane (16534-GUK, Sartorius AG, Göttingen, Germany) and stored at $-20^{\circ} \mathrm{C}$ until further analysis.

Folate was quantified by a microbiological assay based on the AOAC official method method 944.12 and 960.46 for folate quantification (Iyer and Tomar, 2009) using the Vitafast folic acid test kit (P1001, R-Biopharm, Pfungstadt, Germany) per the manufacturer's instructions. Fundamentally, the extracted folates are added to a microtiter plate's wells that are coated with indicator bacteria (the folate-consuming bacteria Lactobacillus rhamnosus) and then incubated in the dark at $37^{\circ} \mathrm{C}$ for $44 \sim 48 \mathrm{~h}$. The growth of the indicator bacteria will depend on the supply of folate present in the sample and is measured by determining the turbidity at $610 \sim 630 \mathrm{~nm}$ using a micro- titer plate reader (iMark, Bio-Rad Laboratories Inc., Hercules, CA, USA). The folate concentration is calculated from a standard curve constructed from different known folate concentrations measured similarly to the samples.

\section{Measurement of LAB growth}

The LAB growth was measured using two methods, i.e., $\mathrm{OD}_{580}$ measurements and the enumeration of CFU. The $\mathrm{OD}_{580}$ was measured using a ultraviolet-Visible spectrophotometer; this method was used as an initial screening for LAB growth in folate-free medium. The number of CFUs was determined by the serial dilution plating method on MRSA and incubation at $37^{\circ} \mathrm{C}$ for $48 \mathrm{~h}$. The number of colonies that grew on the plates is expressed in $\log \mathrm{CFU} / \mathrm{mL}$. These LAB counts were performed for growth in folate-free medium and fermented milk.

\section{Acidity measurements}

The acidity of a medium was measured by its $\mathrm{pH}$ value and titratable acidity. The $\mathrm{pH}$ of the reconstituted skim milk was determined using a pH meter (Eutech pH 700, Thermo Fisher Scientific, Waltham, MA, USA) previously calibrated at $\mathrm{pH} 4$ and 7 using buffer standards. For titratable acidity, the sample was titrated using $0.1 \mathrm{~N} \mathrm{NaOH}$ with phenol-phthalein as the indicator of endpoint. Titratable acidity was calculated as a percentage of lactic acid in the medium.

\section{Data analysis}

The research data are expressed as the mean \pm standard deviation (SD) and were analyzed using SPSS 20.0 (IBM Corp., New York, NY, USA) with the statistical significance set at $P<0.05$. The differences in the LAB growth in FACM and MRSB were evaluated by paired $t$-tests. A one-way ANOVA was used to compare the differences between extracellular folate production in FACM after $16 \mathrm{~h}$ growth and in reconstituted skim milk after $48 \mathrm{~h}$ and various other fermentation times. A two-way ANOVA followed by a Duncan's test was applied to analyze the effect of the folate precursors on folate concentrations in the reconstituted skim milk.

\section{RESULTS AND DISCUSSION}

Growth of folate-producing $L A B$ in folate-free medium Among the $18 \mathrm{LAB}$ isolates tested, only 8 showed relatively high growth in FACM, with $\mathrm{OD}_{580}$ values $>1.00$ after $16 \mathrm{~h}$ of growth (Fig. 1). Lactobacillus fermentum BK27 and JK13, Lactobacillus plantarum 4C261 and JK16, Lactobacillus rhamnosus R23, Pediococcus acidilactici NG64, Lactobacillus brevis BG7, and Leuconostoc mesenteroides S2SR08 had high absorbance values after incubation for $16 \mathrm{~h}$ in FACM, thus exhibiting their potential for producing fo- 


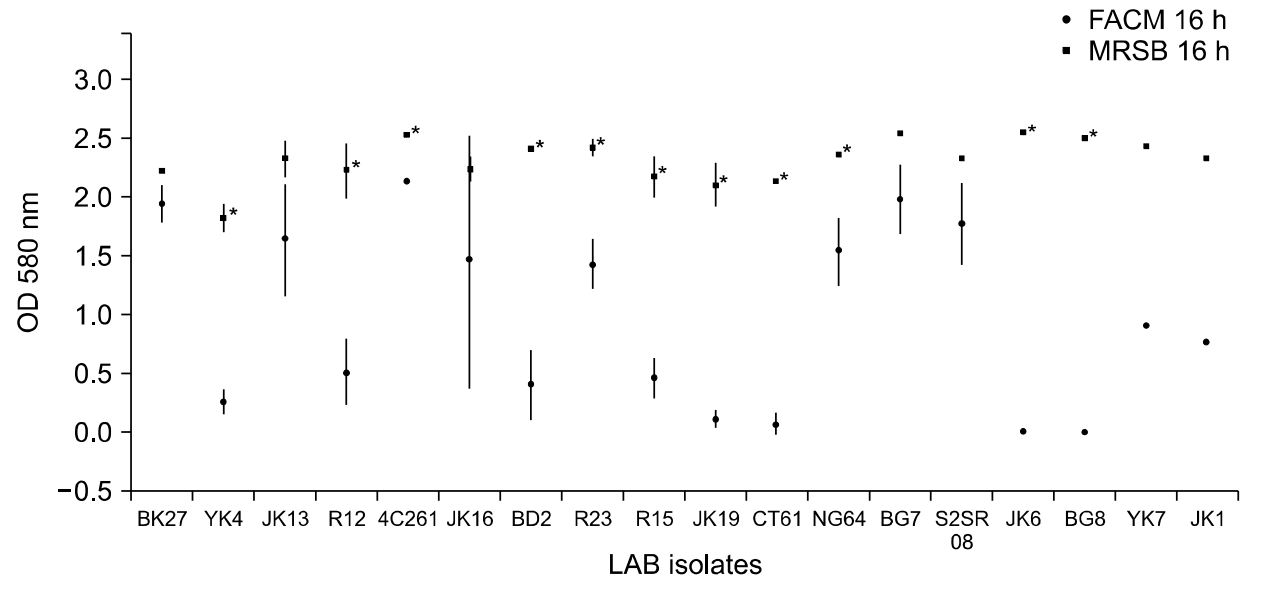

Fig. 1. The growth of lactic acid bacteria (LAB) after $16 \mathrm{~h}$ in folic acid casei medium (FACM; black circles) and de Man, Rogosa, and Sharpe broth (MRSB; black squares), as quantified by the $\mathrm{OD}_{580}$ value. Asterisks $\left(^{*}\right)$ indicate statistical differences between the media for each strain as determined by paired $t^{-}$ tests $(P<0.05)$. late. The growth of the remaining 10 LAB isolates appeared highly dependent on the availability of folate in the medium, as indicated by low absorbances in FACM, but very high absorbances in MRSB. The absorbances of the cultures grown in FACM did not surpass those grown in MRSB, thus indicating they did not grow as well in FACM as they did in MRSB.

Most LAB are classified as folate-dependent bacteria due to the presence of the $f m t$ gene, a signature gene for folate requirement. This gene encodes methionyl-tRNA formyltransferase (EC 2.1.2.9), an enzyme that converts methionyl-tRNA to $\mathrm{N}$-formyl-methionyl transfer RNA (de Crécy-Lagard et al., 2007), which plays a role in the initiation of protein synthesis and cannot be supplemented in the bacterial growth media. Hence, folate is highly essential for the growth of LAB (Harvey, 1973). The ability of a LAB to grow in folate-free medium indicates that it can synthesize folate, and thus be classified as a folateproducing LAB. Therefore, growing the microorganisms in FACM can be used to screen for folate-producing bacteria, as only folate producers will grow in the medium, while non-folate producers will not survive. Fig. 1 shows that some LAB isolates grew well in FACM and were therefore considered folate-producing LAB, while others could not and were thus considered non-folate-producing LAB.

Many similar studies (Laiño et al., 2012; Laiño et al., 2014; Greppi et al., 2017; Meucci et al., 2018) have used FACM as a test medium for the initial screening step for folate-producing LAB. Despite having neither folate nor glutamic acid, the FACM technical datasheet states that it still contains $2 \mathrm{mg} / \mathrm{L}$ of PABA, which is one of the precursors for folate formation; virtually no lactobacilli (except Lac. plantarum) are able to synthesize PABA de novo since they do not have all the types of enzymes required for its production. Therefore, most lactobacilli cannot produce folate in the absence of PABA (Rossi et al., 2011; Greppi et al., 2017). However, not all the LAB isolates tested in this study grew well in the FACM medium, despite PABA being available. The inability of some LAB to utilize the PABA in the FACM medium for folate biosynthesis shows that they can be categorized as a group of auxotrophic folate bacteria.

The use of a LAB with potential as a probiotic such as Lac. plantarum 4C261 (Kurnia et al., 2018) and R12 (Hartanti, 2007), cholesterol-lowering activity such as Lac. rhamnosus R23 (Maryati et al., 2016) and BD2 (Yusuf et al., 2019), or the ability to prevent diarrhea such as Lac. rhamnosus R23 (Nuraida et al., 2012) would be considered to provide added value when producing fermented milk with high folate content and other health benefits. Lac. plantarum 4C261 and Lac. rhamnosus R23 grew well in the FACM medium, indicating they are folate producers.

\section{LAB growth and extracellular folate production in folate- free medium}

Eight LAB isolates with good growth in FACM, as demonstrated by high absorbance values, and three isolates from the Lac. plantarum and Lac. rhamnosus species (R12, $\mathrm{BD} 2$, and R15) with low absorbance values were further evaluated for extracellular folate production in FACM. Nine isolates (Lac. plantarum 4C261, JK16, and R12; Lac. rhamnosus R23; Lac. fermentum JK13 and BK27; Lac. brevis BG7; Ped. acidilactici NG64; and Leu. mesenteroides S2SR08) grew well in FACM, with the counts ranging from 8.43 $9.65 \log \mathrm{CFU} / \mathrm{mL}$. Two other isolates (Lac. rhamnosus R15 and $\mathrm{BD} 2$ ) showed poorer growth, with counts ranging from $5.18 \sim 6.42 \log \mathrm{CFU} / \mathrm{mL}$ (Fig. 2). The LAB isolates with higher counts in FACM also showed the ability to produce extracellular folate at higher levels in the medium after $16 \mathrm{~h}$ of incubation. The high concentrations of extracellular folate produced ranged from 12.42 24.27 $\mathrm{ng} / \mathrm{mL}$. In contrast, Lac. rhamnosus R15 and BD2 showed very little or undetected extracellular folate production in the medium.

Almost none of the lactobacilli (except Lac. plantarum) were able to produce folate due to their lack of enzymes for PABA production (Rossi et al., 2011). However, despite being cultivated in FACM media containing PABA, many strains and species of lactobacilli still cannot bio- 

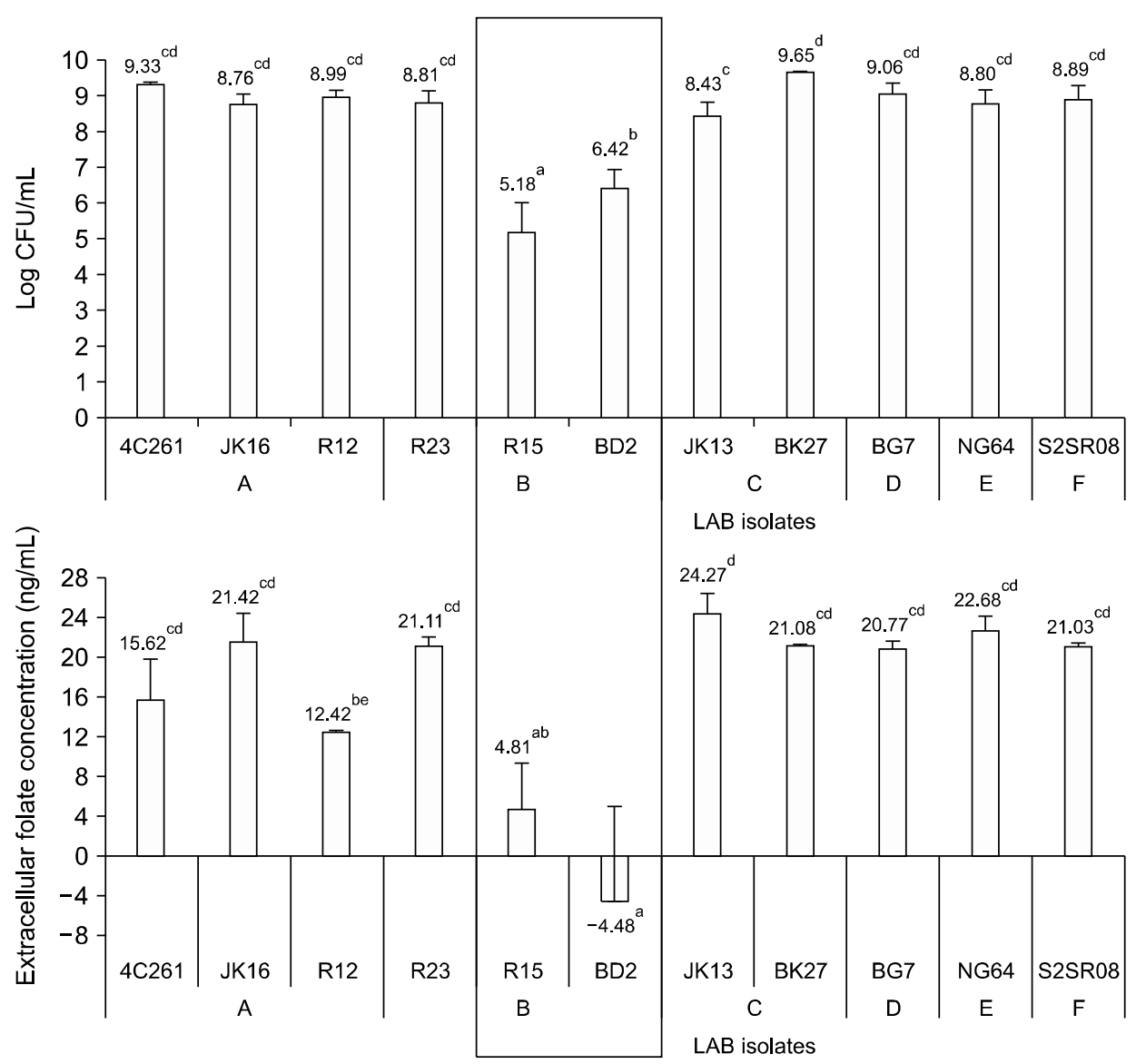

Fig. 2. Growth (log CFU/mL) and extracellular folate concentration of 10 lactic acid bacteria ( $L A B$ ) isolates within 6 different species incubated in folic acid casei medium (FACM) for 16 h. (A) Lactobacillus plantarum, (B) Lactobacillus rhamnosus, (C) Lactobacillus fermentum, (D) Lactobacillus brevis, (E) Pediococcus acidilactici, (F) Leuconostoc mesenteroides. The different letters (ad) above the bars show significant differences between the means ( $P<$ 0.05).

synthesize folate (Laino et al., 2014). In this study, four lactobacilli species (Lac. plantarum, Lac. rhamnosus, Lac. fermentum, and Lac. brevis) and two other LAB species (Ped. acidilactici and Leu. mesenteroides) produced relatively high concentrations of extracellular folate when grown in FACM for $16 \mathrm{~h}$ (Fig. 2). The folate production for these results were higher than that of the folate producer Lactococcus lactis NIZO 9000 which produced folate at $9.3 \mathrm{ng} /$ $\mathrm{mL}$ as reported by Gangadharan et al. (2010), and also reported in some other previous studies. Laiño et al. (2014) reported that after $16 \mathrm{~h}$ growth in FACM, only 1 of 12 strains of Lac. fermentum produced extracellular folate $(4.3 \mathrm{ng} / \mathrm{mL})$, while others did not. Fifteen of 18 strains of Lac. plantarum produced extracellular folate (ranging from $0.3 \sim 22.9 \mathrm{ng} / \mathrm{mL}$ ), while the other 3 did not. Albano et al. (2020) reported that after $24 \mathrm{~h}$ of growth in MRSB, 1 of 5 strains of Lac. rhamnosus produced a moderate amount of extracellular folate $(10.00 \mathrm{ng} / \mathrm{mL})$, while the others only produced $0.0 \sim 2.6 \mathrm{ng} / \mathrm{mL}$. Moreover, Greppi et al. (2017) reported that after $24 \mathrm{~h}$ of growth in MRSB, 10 of 16 strains of Ped. acidilactici produced total folate values between 0.9 and $16.5 \mathrm{ng} / \mathrm{mL}$, while the 6 other strains consumed folate. The extracellular folate production by Lac. brevis in this study was higher than that in a previous study (Salvucci et al., 2016), which reported that Lac. brevis ES253 produced $7.3 \mathrm{ng} / \mathrm{mL}$ of folate after an $18 \mathrm{~h}$ incubation. Furthermore, our study may be the first to report that the Leu. mesenteroides strain can produce a high level of extracellular folate, as this species has not been studied and reported as a folate producer in previous publications.

Conversely, other studies have also shown higher folate production compared to the present results. These previous studies used a similar medium, but different incubation times. For example, Lac. plantarum 6.2 produced around $40 \mathrm{ng} / \mathrm{mL}$ of folate after $10 \mathrm{~h}$ of incubation (Greppi et al., 2017), Lac. rhamnosus IFM4 produced $35 \mathrm{ng} / \mathrm{mL}$ after $18 \mathrm{~h}$ (Panda et al., 2018), Lac. fermentum 8.2 produced $\sim 30 \mathrm{ng} / \mathrm{mL}$ after $11 \mathrm{~h}$ (Greppi et al., 2017), and Ped. acidilactici ES22 produced $27.1 \mathrm{ng} / \mathrm{mL}$ after $18 \mathrm{~h}$ (Salvucci et al., 2016). Differences in incubation times may affect the folate production of each strain (Lin and Young, 2000; Laiño et al., 2012; Divya and Nampoothiri, 2015; Greppi et al., 2017). Therefore, determining the optimum incubation time for each LAB strain producing extracellular folate is necessary to obtain the highest levels of folate production.

Fig. 2 shows that some strains from the same species exhibited similar abilities in synthesizing extracellular folate, whereas others differed. The three strains of Lac. plantarum (4C261, JK16, and R12) had similar abilities to produce extracellular folate. Although Lac. plantarum JK16 produced more folate than the other strains, the difference was not significant. The ability of Lac. fermentum 
JK13 to produce extracellular folate was also similar to that of Lac. fermentum BK27. In some cases, different strains from the same species (Lac. rhamnosus R23, R15, and BD2) had differing abilities to produce folate. Among the Lac. rhamnosus strains tested in this study, Lac. rhamnosus R23 produced the highest concentration of extracellular folate, Lac. rhamnosus R15 produced the lowest concentration, and Lac. rhamnosus BD2 did not produce a detectable amount of folate. Laiño et al. (2012) have also reported that several strains of $36 \mathrm{LAB}$ grown in folatefree medium produced very high concentrations of extracellular folate, while other strains synthesized small amounts and were almost undetectable. Our findings are also in agreement with those of Laiño et al. (2012). Even so, the data are not sufficient to draw the conclusion that the ability to produce folate among LAB is strain-dependent.

Fig. 2 also shows the extracellular folate levels of LAB incubated in FACM in relation to their growth. The LAB isolates with higher extracellular folate concentrations had higher LAB counts, while the isolates with lower extracellular folate levels had lower counts. According to Rossi et al. (2011), a microorganism will synthesize specific metabolites (such as folate) to meet its own needs to support growth. In describing the folate biosynthetic pathway in microbial cells, Wegkamp et al. (2007) stated that it occurs by the conversion of glutamyl transpeptidase (GTP) via several steps to the cofactor THF, which is then converted to 1-carbon carriers such as 5-MTHF, 10-formyl-THF, 5,10-methenyl-THF, and 5,10-methyleneTHF in a 1-carbon pathway. These components play a role in several metabolic reactions such as the synthesis of purines, pyrimidines, and amino acids and the initiation of the protein synthesis needed for cell growth. Therefore, the folate synthesized by LAB will correlate with their growth.

\section{Folate production and LAB growth in reconstituted skim milk}

The isolate with the highest level of extracellular folate production (Lac. fermentum JK13) and two other isolates with potential as probiotics (Lac. plantarum 4C261 and Lac. rhamnosus R23) were selected for application in the fermentation of reconstituted skim milk. Fig. 3A shows that Lac. fermentum JK13, Lac. plantarum 4C261, and Lac. rhamnosus $\mathrm{R} 23$ had the same behavior when cultivated in reconstituted skim milk for $48 \mathrm{~h}$. The three isolates tended to consume the folate in the medium, but by different amounts. Compared to the initial folate concentration before fermentation, the extracellular folate concentration in the reconstituted skim milk fermented by Lac. fermentum JK13 drastically decreased by $61.01 \%$, which was followed by a $49.18 \%$ decrease in Lac. plantarum 4C261, and $27.35 \%$ in Lac. rhamnosus R23. The de- creased folate levels in the fermented skim milk were in line with their growth (Fig. 3B), with the LAB counts ranging from $8.28 \sim 9.09 \log \mathrm{CFU} / \mathrm{mL}$. The growth of Lac. fermentum JK13, Lac. plantarum 4C261, and Lac. rhamnosus R23 in reconstituted skim milk increased acidity, as shown by the decreased $\mathrm{pH}$ values (Fig. $3 \mathrm{C}$ ) and rise in titratable acidity (Fig. 3D). After $48 \mathrm{~h}$ of fermentation, the $\mathrm{pH}$ values decreased to a range of 4.01 5.45 due to the increase in titratable acidity, which ranged from 0.64 $\sim 1.24 \%$. The fermented milk was acidified due to LAB activities in degrading lactose into lactic acid. Milk is the most suitable medium for $\mathrm{LAB}$, but the reconstituted skim milk used contained $41.1 \mathrm{ng} / \mathrm{mL}$ of folate (based on the results of this study) and $8.53 \mathrm{mg} / \mathrm{mL}$ of glutamate (as stated in the nutritional composition of NZMP skim milk products). Our results indicate the folate initially present in the skim milk was sufficient to support the growth of the LAB isolates, hence they did not synthesize folate, and the folate concentration did not increase during fermentation.

The present study indicates that folate production in the 3 folate-producing LAB isolates was metabolically regulated, and their cells synthesized folate efficiently. As folate biosynthesis requires energy expenditure, the 3 isolates tended to utilize folate for their growth when a sufficient amount was available in the medium, resulting in the lowering of folate levels (Fig. 3). According to Deguchi et al. (1985), bacteria can show little or an absence of vitamin biosynthesis when growing in vitaminrich environments. However, this might not occur in all bacteria species. As shown by Pompei et al. (2007), some bifidobacteria strains do not produce folate when the vitamin is available in the medium, while other strains continue to synthesize it. This suggests that the folate biosynthesis process is regulated differently in the several strains. However, according to Vinnicombe and Derrick (1999), during folate biosynthesis in Streptococcus pneumoniae, in addition to dihydropteroate (as the reaction product), folate and its reduced derivatives (such as dihydrofolate and THF) can also inhibit the performance of dihydropteroate synthase, which catalyzes the conversion of 6-hydroxymethyl-7,8-dihydropterin pyrophosphate together with PABA to dihydropteroate. Furthermore, Sybesma et al. (2003) have reported that THF can inhibit folate biosynthesis through the enzymatic feedback inhibition mechanism, namely DHFR, which catalyzes the conversion of dihydrofolate to THF. It was proven by the overexpression of folA (the gene encoding the DHFR enzyme), resulting in a twofold decline in folate production. This could also explain the feedback inhibition in folateproducing LAB when they grow in folate-rich medium, as the presence of folate would inhibit the LAB's folate production. 

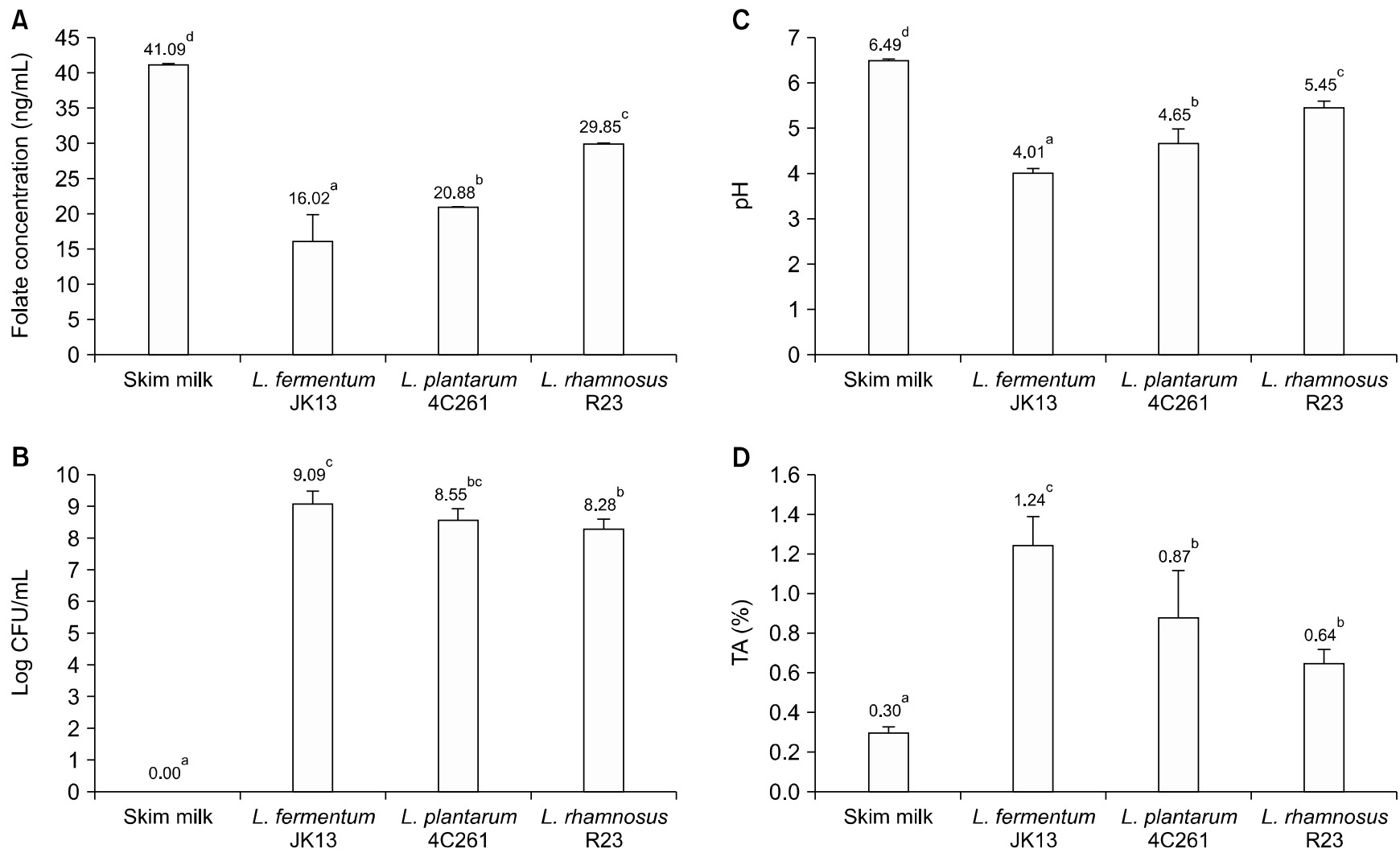

Fig. 3. Folate concentration $(A)$, lactic acid bacteria $(L A B)$ count $(B), p H$ value $(C)$, and titratable acidity $(T A)(D)$ of the $L A B$ isolates in reconstituted skim milk after $48 \mathrm{~h}$ of fermentation. The different letters ( $\mathrm{a}-\mathrm{d}$ ) above the bars show significant differences between the means $(P<0.05)$.

\section{Effect of folate precursors on folate concentration in the fermentation of reconstituted skim milk}

Despite their inability to elevate folate levels in fermented milk, the addition of PABA and glutamate reduced folate consumption by Lac. fermentum JK13, Lac. plantarum 4C261, and Lac. rhamnosus R23, with significantly different effects among the three isolates (Fig. 4A). Folate consumption by Lac. fermentum JK13 and Lac. plantarum 4C261 in skim milk supplemented with PABA was reduced by $6 \sim 8 \mathrm{ng} /$ $\mathrm{mL}$ to values that were lower than those of the $3 \mathrm{LAB}$ grown in reconstituted skim milk without precursors, i.e., $20.21 \sim 25.07 \mathrm{ng} / \mathrm{mL}$. However, the addition of PABA had no effect on Lac. rhamnosus R23. The addition of glutamate to the skim milk also lowered folate utilization by the 3 $\mathrm{LAB}$, but with rates only $2 \sim 4 \mathrm{ng} / \mathrm{mL}$ lower than those in the skim milk without supplementation. Milk supplemented with glutamate that was fermented by Lac. rhamnosus R23 had the lowest level of folate consumption, amounting to $8.92 \mathrm{ng} / \mathrm{mL}$.

As shown in Fig. 4B, the addition of folate precursors to the reconstituted skim milk did not affect the $\mathrm{pH}$ of the medium after fermentation by the 3 isolates. The $\mathrm{pH}$ values of the different media ranged from 3.97 4.09 for Lac. fermentum JK13, 4.42 4.62 for Lac. plantarum 4C261, and 5.25 5.31 for Lac. rhamnosus R23.

Despite the availability of folate in the medium, supplementing the reconstituted skim milk with PABA and glutamate as folate precursors for folate biosynthesis was expected to increase folate production by the $3 \mathrm{LAB}$, as most $\mathrm{LAB}$, especially those from the lactobacilli group, are unable to synthesize PABA (Rossi et al., 2011) and glutamate (Lapujade et al., 1998). However, the result of this study indicates that supplementation did not drive an overproduction of folate in Lac. fermentum JK13, Lac. plantarum 4C261, or Lac. rhamnosus R23. In fact, folate concentrations in the fermented skim milk were much lower than the initial folate concentration before fermentation. This is probably due to the relatively low level of folate requirements for the 3 isolates, with the available folate in the milk being sufficient to meet their needs. Therefore, the presence of folate precursors did not affect the folate biosynthesis process in their cells. This result is in line with that of Rao et al. (1984), who reported that for Lac. bulgaricus fermenting milk for $48 \mathrm{~h}$, the addition of folate precursors such as PABA and GTP did not increase the folate concentration, with the isolate continuing to consume folate in the medium.

\section{Effect of fermentation time on the folate concentration of reconstituted skim milk}

Since Lac. fermentum JK13 consumed the highest amount of folate during milk fermentation, it was excluded from the study of the effect of fermentation time. The folate concentrations relative to the growth of Lac. plantarum 
A

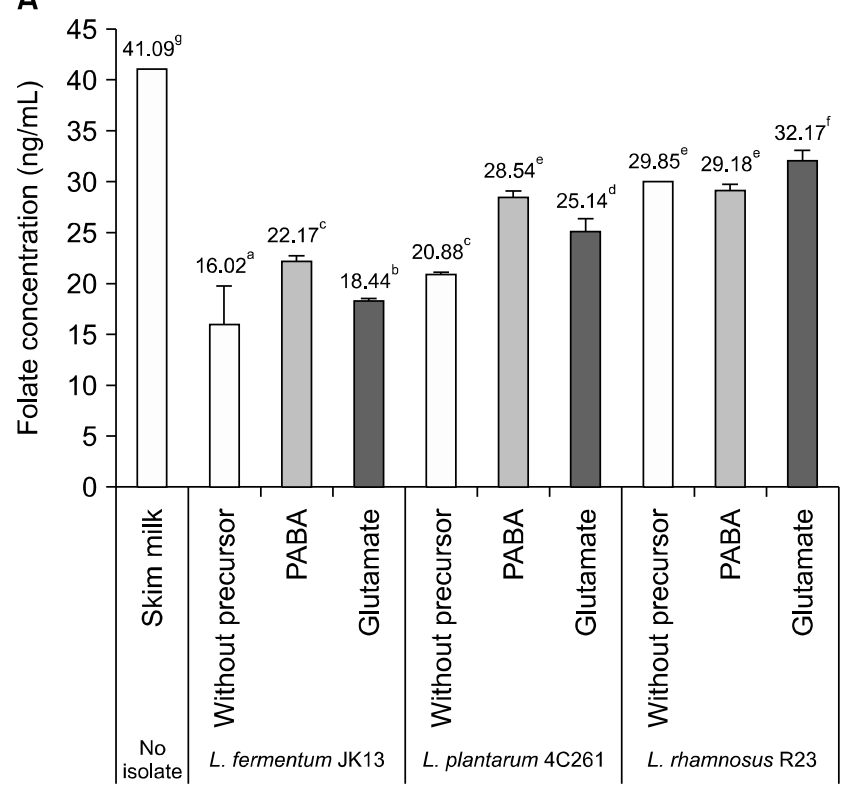

B

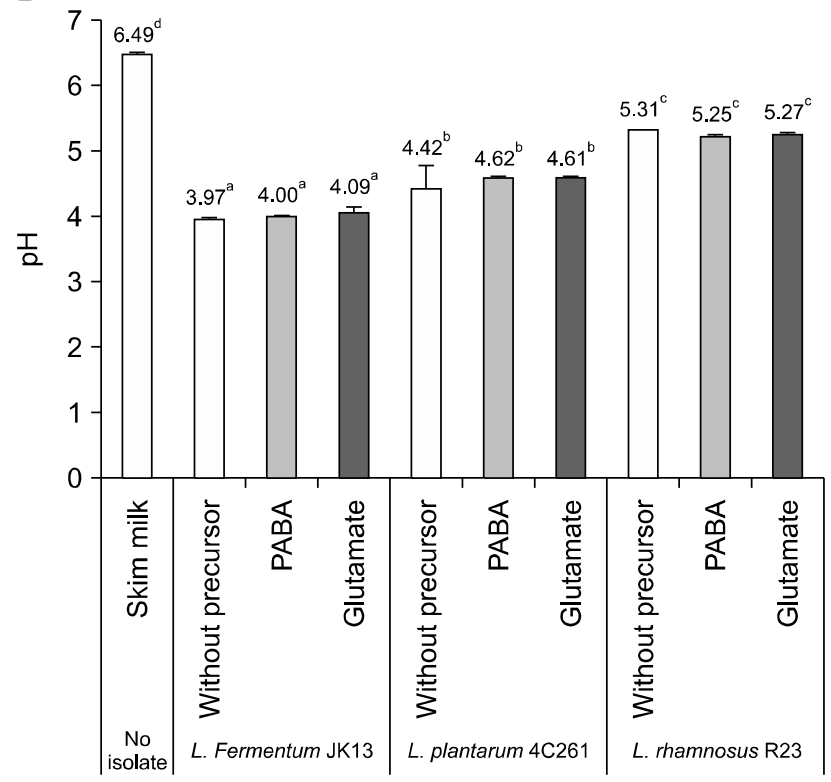

Fig. 4. Folate concentration (A) and $\mathrm{pH}$ value $(\mathrm{B})$ in reconstituted skim milk after $48 \mathrm{~h}$ of fermentation by 3 lactic acid bacteria isolates without supplementation (white bars) and after the addition of $p$-aminobenzoic acid (PABA; hatched bars) or glutamate (dotted bars). The different letters (a-g) above the bars show the significant differences between the means $(P<0.05)$.

A

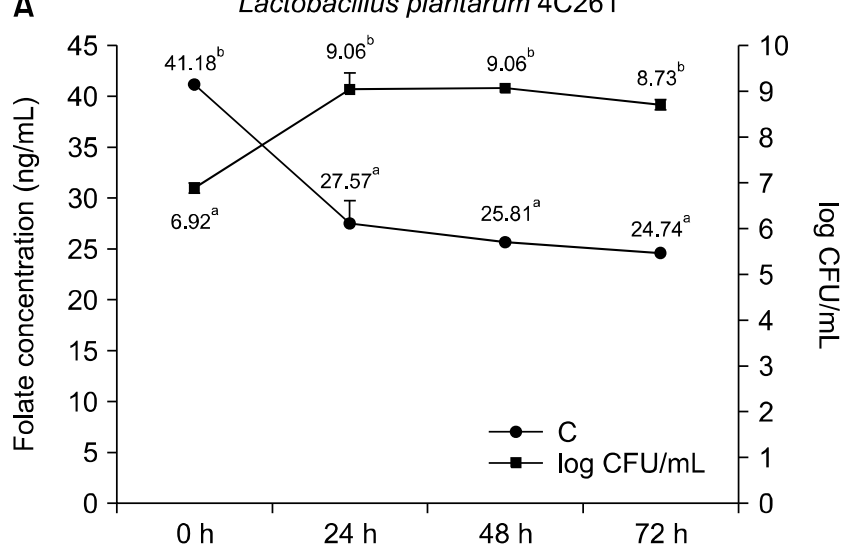

C

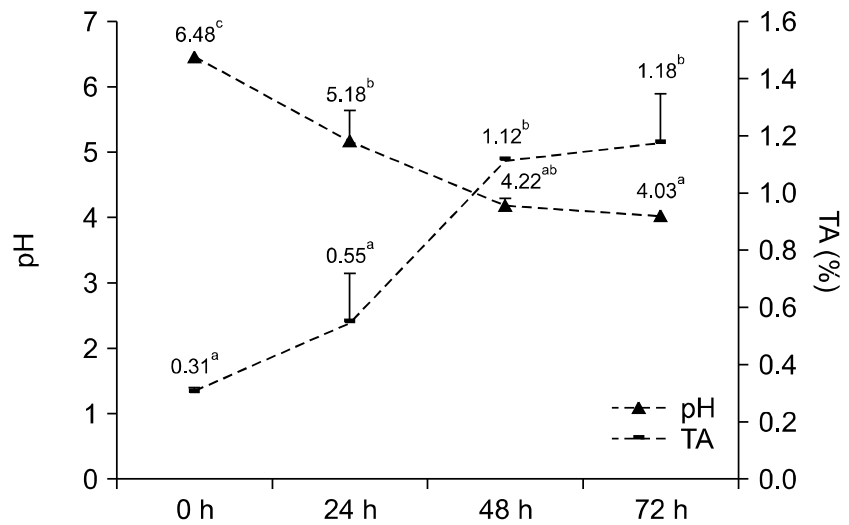

B

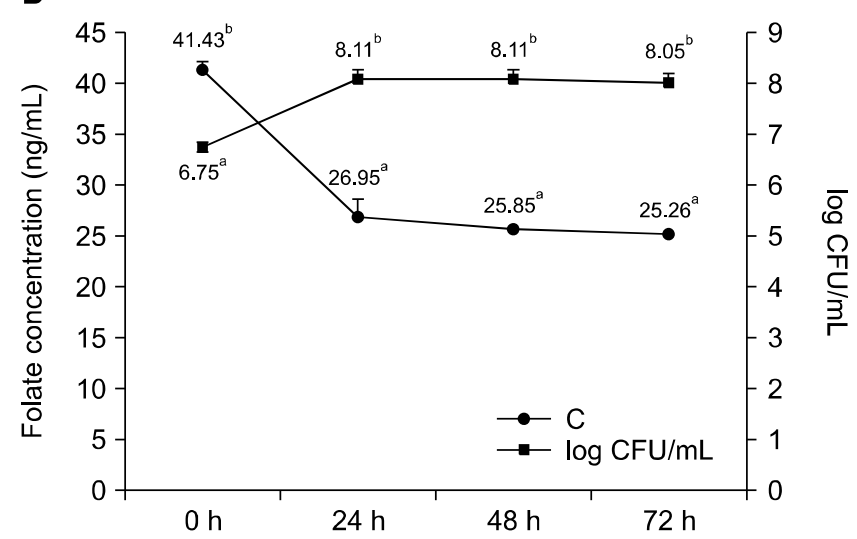

D

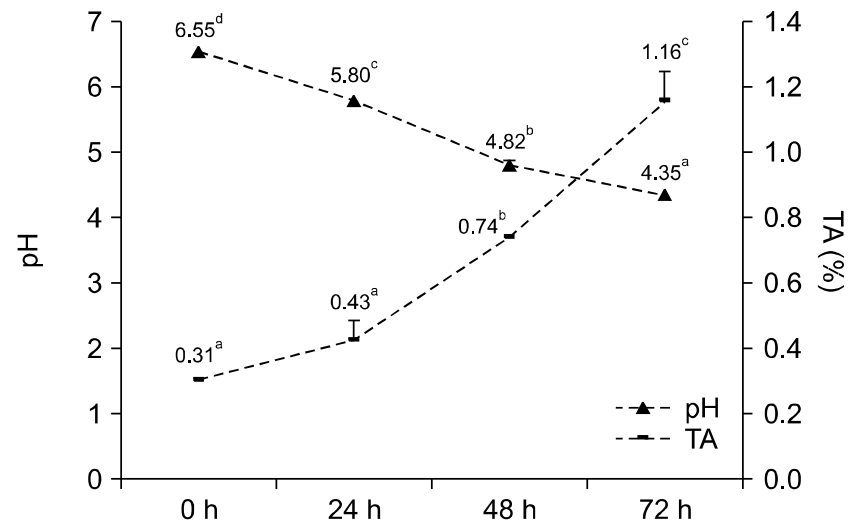

Fig. 5. (A and B) Folate concentration, lactic acid bacteria growth (log CFU/mL), (C and D) pH, and titratable acidity (TA) values of skim milk fermented by $4 C 261$ and R23 at various fermentation times. The different letters (a-d) above the lines indicate significant differences between the means $(P<0.05)$. 
4C261 and Lac. rhamnosus R23 in reconstituted skim milk after $0,24,48$, and $72 \mathrm{~h}$ of fermentation are presented in Fig. 5. Compared to the initial folate concentration, the folate levels in the reconstituted skim milk fermented by the two isolates were drastically decreased by $33 \sim 35 \%$ after $24 \mathrm{~h}$ of incubation and then remained constant for up to $72 \mathrm{~h}$, at which time the folate concentrations had a range of $24.74 \sim 25.26 \mathrm{ng} / \mathrm{mL}$. However, the LAB counts for the lactobacilli indicated that Lac. plantarum 4C261 and Lac. rhamnosus $\mathrm{R} 23$ had reached the stationary growth phase by $24 \mathrm{~h}$, and they remained stable for up to $72 \mathrm{~h}$. During the growth period, the $\mathrm{pH}$ levels continuously decreased until reaching their lowest values of 4.03 and 4.35, respectively, with the titratable acidity progressively increasing until reaching their highest values of $1.18 \%$ and $1.16 \%$, respectively, after $72 \mathrm{~h}$ of fermentation.

The folate consumption by Lac. plantarum 4C261 and Lac. rhamnosus $\mathrm{R} 23$ related to their growth, as shown by the dramatic folate concentration reduction in the medium along with the sharp rise in the LAB counts until 24 $\mathrm{h}$, after which, both remained constant until $72 \mathrm{~h}$. This correlation indicates that the folate consumed by the LAB was used for their growth.

In conclusion, folate-producing and non-producing lactobacilli strains are found among LAB isolated from various local food sources. The 3 isolates with the highest folate production (Lac. fermentum JK13 from kefir granules; Lac. plantarum 4C261 from salted mustard, and Lac. rhamnosus R23 from breast milk) only produced folate in the absence of folate in the medium, and their ability to produce folate is sensitive to the presence of even a small amount of folate in the medium. Supplementing the milk with folate precursors did not induce folate production in the 3 isolates. These findings could be further elucidated by an in-depth study on the regulation of folate biosynthesis, particularly on the feedback inhibition mechanism. The secretion of extracellular folate is affected by the strength of the cell membrane. Therefore, an effort to weaken the cell membrane without significantly affecting bacterial growth may be a possible strategy to increase folate production and secretion while extending fermentation time.

\section{ACKNOWLEDGEMENTS}

The authors would like to thank the Ministry of Research, Technology and Higher Education of the Republic of Indonesia for their financial support in the research scheme of Master of Education towards Doctoral Scholarship Program for Excellence Undergraduate (PMDSU), under contract no.: 3/E1/KP.PTNBH/2019.

\section{AUTHOR DISCLOSURE STATEMENT}

The authors declare no conflict of interest.

\section{REFERENCES}

Albano C, Silvetti T, Brasca M. Screening of lactic acid bacteria producing folate and their potential use as adjunct cultures for cheese bio-enrichment. FEMS Microbiol Lett. 2020. 367: fnaa059. https://doi.org/10.1093/femsle/fnaa059

Castaño E, Piñuñuri R, Hirsch S, Ronco AM. Folate and pregnancy, current concepts: it is required folic acid supplementation?. Rev Chil Pediatr. 2017. 88:199-206.

Crider KS, Bailey LB, Berry RJ. Folic acid food fortification -its history, effect, concerns, and future directions. Nutrients. 2011. 3:370-384

Crider KS, Yang TP, Berry RJ, Bailey LB. Folate and DNA methylation: a review of molecular mechanisms and the evidence for folate's role. Adv Nutr. 2012. 3:21-38.

de Crécy-Lagard V, El Yacoubi B, de la Garza RD, Noiriel A, Hanson AD. Comparative genomics of bacterial and plant folate synthesis and salvage: predictions and validations. BMC Genomics. 2007. 8:245. https://doi.org/10.1186/1471-21648-245

Deguchi Y, Morishita T, Mutai M. Comparative studies on synthesis of water-soluble vitamins among human species of bifidobacteria. Agric Biol Chem. 1985. 49:13-19.

Delchier N, Herbig AL, Rychlik M, Renard CMGC. Folates in fruits and vegetables: contents, processing, and stability. Compr Rev Food Sci Food Saf. 2016. 15:506-528.

Divya JB, Nampoothiri KM. Folate fortification of skim milk by a probiotic Lactococcus lactis CM28 and evaluation of its stability in fermented milk on cold storage. J Food Sci Technol. 2015. 52:3513-3519.

Gangadharan D, Sivaramakrishnan S, Pandey A, Nampoothiri KM. Folate-producing lactic acid bacteria from cow's milk with probiotic characteristics. Int J Dairy Technol. 2010. 63:339-348.

Greppi A, Hemery Y, Berrazaga I, Almaksour Z, Humblot C. Ability of lactobacilli isolated from traditional cereal-based fermented food to produce folate in culture media under different growth conditions. LWT. 2017. 86:277-284.

Hartanti AW. Seleksi bakteri asam laktat yang berpotensi sebagai probiotik dari isolat air susu ibu. Undergraduate thesis. IPB University, Bogor, Indonesia. 2007.

Harvey RJ. Growth and initiation of protein synthesis in Escherichia coli in the presence of trimethoprim. J Bacteriol. 1973. 114:309-322.

Iyer R, Tomar SK. Folate: a functional food constituent. J Food Sci. 2009. 74:R114-R122.

Kurnia H, Nuraida L, Faridah DN. Manfaat bakteri asam laktat asal sawi (Brassica juncea L.) asin dalam menurunkan kolesterol secara in vitro. Undergraduate thesis. IPB University, Bogor, Indonesia. 2019.

Laiño JE, del Valle MJ, de Giori GS, LeBlanc JGJ. Applicability of a Lactobacillus amylovorus strain as co-culture for natural folate bio-enrichment of fermented milk. Int J Food Microbiol. 2014. 191:10-16.

Laiño JE, del Valle MJ, de Giori GS, LeBlanc JGJ. Development of a high folate concentration yogurt naturally bio-enriched using selected lactic acid bacteria. LWT-Food Sci Technol. 2013. 54:1-5.

Laiño JE, Leblanc JG, Savoy de Giori G. Production of natural folates by lactic acid bacteria starter cultures isolated from artisanal Argentinean yogurts. Can J Microbiol. 2012. 58:581-588. 
Laiño JE, Zelaya H, del Valle MJ, de Giori GS, LeBlanc JG. Milk fermented with selected strains of lactic acid bacteria is able to improve folate status of deficient rodents and also prevent folate deficiency. J Funct Foods. 2015. 17:22-32.

Lapujade P, Cocaign-Bousquet M, Loubiere P. Glutamate biosynthesis in Lactococcus lactis subsp. lactis NCDO 2118. Appl Environ Microbiol. 1998. 64:2485-2489.

Lin MY, Young CM. Folate levels in cultures of lactic acid bacteria. Int Dairy J. 2000. 10:409-413.

Maryati Y, Nuraida L, Dewanti-Hariyadi R. A study in vitro of lactic acid bacteria (LAB) isolates on cholesterol lowering ability in the presence of oligosaccharides. Agritech. 2016. 36:196205.

Meucci A, Rossetti L, Zago M, Monti L, Giraffa G, Carminati D, et al. Folates biosynthesis by Streptococcus thermophilus during growth in milk. Food Microbiol. 2018. 69:116-122.

Nuraida L, Hana, Hartanti AW, Prangdimurti E. Potential of Lactobacillus isolated from breast milk to prevent diarrheae. J Teknol dan Industri Pangan. 2012. 23:158.

Nurchandra KP, Nuraida L, Nurjanah S. Identifikasi bakteri asam laktat asal tape dengan menggunakan polymerase chain reaction dan karakterisasi sifat amilolitiknya. Undergraduate thesis. IPB University, Bogor, Indonesia. 2018.

Nygren-Babol L, Jägerstad M. Folate-binding protein in milk: a review of biochemistry, physiology, and analytical methods. Crit Rev Food Sci Nutr. 2012. 52:410-425.

Padalino M, Perez-Conesa D, López-Nicolás R, Frontela-Saseta C, Ros-Berruezo G. Effect of fructooligosaccharides and galactooligosaccharides on the folate production of some folate-producing bacteria in media cultures or milk. Int Dairy J. 2012. 27: 27-33.

Panda SH, Das S, Bal P, Panda SK, Goli JK, Mohanty N. Characterization of novel folate producing Lactobacillus rhamnosus and its appliance in fortification of ragi (Eleusine coracana) gruel. Food Biosci. 2018. 21:100-106.

Patel KR, Sobczyńska-Malefora A. The adverse effects of an excessive folic acid intake. Eur J Clin Nutr. 2017. 71:159-163.

Pompei A, Cordisco L, Amaretti A, Zanoni S, Matteuzzi D, Rossi $M$. Folate production by bifidobacteria as a potential probiotic property. Appl Environ Microbiol. 2007. 73:179-185.

Rao DR, Reddy AV, Pulusani SR, Cornwell PE. Biosynthesis and utilization of folic acid and vitamin B12 by lactic cultures in skim milk. J Dairy Sci. 1984. 67:1169-1174.

Rossi M, Amaretti A, Raimondi S. Folate production by probiotic bacteria. Nutrients. 2011. 3:118-134.

Saini RK, Nile SH, Keum YS. Folates: chemistry, analysis, occurrence, biofortification and bioavailability. Food Res Int. 2016. 89:1-13.

Salvucci E, LeBlanc JG, Pérez G. Technological properties of lactic acid bacteria isolated from raw cereal material. LWT. 2016. 70:185-191.

Sybesma W, Starrenburg M, Kleerebezem M, Mierau I, de Vos WM, Hugenholtz J. Increased production of folate by metabolic engineering of Lactococcus lactis. Appl Environ Microbiol. 2003. 69:3069-3076.

Touw KS, Nuraida L, Suliantari. Identifikasi bakteri asam laktat dominan selama fermentasi tempe dan evaluasi potensinya. Undergraduate thesis. IPB University, Bogor, Indonesia. 2014.

Vinnicombe HG, Derrick JP. Dihydropteroate synthase from Streptococcus pneumoniae: characterization of substrate binding order and sulfonamide inhibition. Biochem Biophys Res Commun. 1999. 258:752-757.

Wegkamp A, van Oorschot W, de Vos WM, Smid EJ. Characterization of the role of para-aminobenzoic acid biosynthesis in folate production by Lactococcus lactis. Appl Environ Microbiol. 2007. 73:2673-2681.

Wright AJ, Dainty JR, Finglas PM. Folic acid metabolism in human subjects revisited: potential implications for proposed mandatory folic acid fortification in the UK. Br J Nutr. 2007. 98:667-675.

Yusuf D, Nuraida L, Dewanti-Hariyadi R, Hunaefi D. In vitro characterization of lactic acid bacteria from Indonesian kefir grains as probiotics with cholesterol-lowering effect. J Microbiol Biotechnol. 2019. 30:726-732.

Yusuf D, Nuraida L, Dewanti-Hariyadi R, Hunaefi D. Lactic acid bacteria and yeasts from Indonesian kefir grains and their growth interaction. Asian J Microbiol Biotechnol Environ Sci. 2020. 22:44-49. 